\title{
O TOMBAMENTO DE IGUAPE COMO PATRIMÔNIO NACIONAL: NOVAS PRÁTICAS E POLÍTICAS DE PRESERVAÇÃO
}

\section{THE PRESERVATION OF IGUAPE AS NATIONAL HERITAGE: NEW PRACTICES AND PRESERVATION POLICIES}

Flávia Brito do Nascimento ${ }^{1}$

Universidade de São Paulo, São Paulo, SP, Brasil, flaviabn@usp.br

Simone Scifoni²

Universidade de São Paulo, São Paulo, Brasil, simone.scifoni@gmail.com

\section{Resumo}

Em dezembro de 2009 o conselho consultivo do Iphan aprovou o tombamento do Centro Histórico de Iguape/SP, numa decisão que trouxe novidades importantes para a política de patrimônio no Estado de São Paulo. Algumas delas são o princípio essencial da interlocução e diálogo local, a inclusão do patrimônio natural como parte integrante dos bens edificados, a construção do estudo feita de modo indissociável da educação patrimonial e o entendimento dos vestígios materiais a partir dos processos históricos e de sua sobreposição espacial. Estas foram decisões metodológicas do estudo de tombamento que foi realizado pelas autoras do artigo como técnicas em patrimônio da Superintendência do Iphan em São Paulo. Tais decisões fundamentaram-se nas muitas transformações do patrimônio cultural como campo disciplinar postas desde a Constituição de 1988. O presente artigo tem por objetivo apresentar e problematizar o processo de patrimonialização do Centro Histórico de Iguape realizado pelo Iphan entre 2007 e 2009, momento em que a instituição renova seus quadros técnicos e busca novos parâmetros de atuação. Com foco nessa experiência de tombamento o trabalho apresenta de forma crítica os resultados de uma política de proteção ao patrimônio nacional.

Palavras-chave: Iguape. Iphan. Políticas de patrimônio.

\begin{abstract}
In December 2009, the Advisory Council of Iphan (Institute for National Artistic and Historical Heritage) voted to list the Historic Center of Iguape, in the state of São Paulo, as a heritage site - in a decision that marked an important new direction in the state's heritage policy. In the first federal-level protection of an urban center in the state, the essential principle of local dialogue, the concept of natural heritage as an integral part of built assets, the fact that the study's approach was inextricably linked to heritage education, and the understanding of material remains within the context of historical processes and their spatial juxtapositions. These were methodological decisions taken by the authors of the article while technicians of the Institute for National Artistic and Historical Heritage that were based on the changes in cultural heritage as a field of study that took place since the Brazilian Constitution of 1988. Focusing on this listing experience, this article aims do present critically the results of a national preservation policy in Brazil.
\end{abstract}

Keywords: Iguape. Iphan. Preservation policies.

How to cite this article:

NASCIMENTO, Flávia Brito do; SCIFONI, Simone. O tombamento de lguape como patrimônio nacional: novas práticas e políticas de patrimônio nacional. PARC Pesquisa em Arquitetura e Construção, Campinas, v. 6, n. 1, p. 26-38, jan./mar. 2015. ISSN 1980-6809 


\section{Introdução}

Embora Iguape estivesse dentre os mais bem preservados e caracterizados centros históricos do Estado, o acautelamento federal não havia se viabilizado até 2009, quando o Conselho Consultivo aprovou seu tombamento. As características físicas do sítio eram, sob muitos aspectos, coerentes com os critérios seletivos adotados pelo Iphan nas primeiras ações de preservação. A sua arquitetura e urbanismo remontam ao período da exploração aurífera e às conquistas do território no século XVI, às atividades ligadas à construção naval no século XVIII e à cultura de arroz no século XIX, as quais estruturadas por trama urbana singular, resultam em núcleo urbano notável no contexto das cidades da América Portuguesa. Mas as políticas públicas de preservação no Estado de São Paulo não priorizaram a atuação em favor da preservação de núcleos urbanos, nem o olhar para o Vale do Ribeira.

A proposta de preservação foi por nós elaborada na condição de corpo técnico do Iphan em São Paulo. ${ }^{1}$ A proposta esteve consonância com as políticas de patrimônio cultural do Depam (Departamento de Patrimônio Material e Fiscalização) nos anos 2000, trouxe novidades importantes para os estudos e políticas de preservação, que nos parecem ser de três ordens.

A primeira delas refere-se à história institucional da Superintendência do Iphan em São Paulo, dentre as representações regionais mais antigas e tradicionais da Instituição (juntamente com Minas Gerais, Rio de Janeiro e Bahia), que por razões que veremos adiante, não havia protegido nenhum centro urbano como patrimônio nacional até 2009. As razões do primeiro tombamento em São Paulo depois de 80 anos de trajetória institucional merecem problematização e ajudam a compreender a história das políticas públicas para o patrimônio cultural.

O segundo aspecto inovador do tombamento de Iguape relaciona-se à escolha da área de atuação. Situada no Vale do Ribeira, ao sul do estado na divisa com o Paraná, a região apresenta os menores índices de desenvolvimento econômico, uma vez que ficou às margens da força econômica do café. Contando com núcleos urbanos que remontam aos primeiros momentos da ocupação do território pela Coroa Portuguesa, o Vale do Ribeira foi se organizando, ao longo do tempo, em torno de uma população de caiçaras, quilombolas, ribeirinhos e imigrantes, cujas representações e protagonismo como patrimônio cultural pareceram campo fértil para políticas de inclusão e desenvolvimento econômico pela via da preservação.
O terceiro aspecto singular do processo de preservação legal de Iguape foi a concepção do estudo. Sua fundamentação teórica e o critério de valoração teve lastro nas muitas transformações do patrimônio cultural como campo disciplinar, postas em evidência desde a Constituição de 1988. Diante das dificuldades de romper internamente com a visão calcada na "ortodoxia do patrimônio", para usar as palavras de Rodrigues (2000) que buscava nos núcleos tradicionais coerência estilística, o estudo de tombamento passou a compreender seu valor nos processos sociais de urbanização da cidade, contemplando suas muitas expressões materiais, bem como a sua sobreposição. Outro aspecto fundamental do estudo foi a sua construção de modo indissociável da educação patrimonial, em diálogo constante com a população local, tendo como parceiro a Prefeitura Municipal, apoiando com recursos e logísticas.

A articulação destes três aspectos configurou uma metodologia de trabalho inovadora em relação ao que vinha sendo feito e cujos resultados puderam ser apreciados em rápido espaço de tempo para o seu tombamento, revertendo igualmente de modo efetivo em políticas públicas de preservação.

\section{Os caminhos para o tombamento de lguape na história das políticas de patrimônio cultural em São Paulo}

A superintendência do Iphan em São Paulo é contemporânea à criação do Serviço do Patrimônio Histórico e Artístico Nacional, Sphan, atualmente Iphan. Dentre os Estados merecedores uma diretoria local para inventariar e preservar o patrimônio, a "regional de São Paulo", como ficou conhecida, contou com a coordenação de Mário de Andrade na estruturação dos critérios seletivos da primeira listagem de bens a preservar (GONÇALVES, 2007).

Fundamentado em parâmetros da constituição do patrimônio nacional brasileiro já descritos por diversos autores, Mário de Andrade tratou de buscar em São Paulo o Brasil colonial. A unidade via arquitetura colonial e barroca era representada em sua essência pelas cidades mineiras, era um ideal a ser buscado para configurar a unidade nacional e representar sua materialidade. Nos primeiros documentos e relatórios encaminhados por Mário a Rodrigo Melo Franco já está claro que haveria dificuldades na empreitada. $\mathrm{Na}$ ausência do fausto da região mineira de exploração de ouro, Mário sugere que a saída para os tombamentos em São Paulo seria o livro histórico (RUBINO, 1991). 
Dessa forma, no mapa do patrimônio nacional o estado de São Paulo foi marcado pela arquitetura da taipa de pilão das casas bandeiristas. De características austeras que coadunavam com os valores compartilhados pelos arquitetos modernos do Sphan, ao mesmo tempo, eram portadoras de valor histórico fundamental para o Estado. A constituição da identidade bandeirista se organizava em paralelo à fundação do órgão de patrimônio nacional, e a proteção da materialidade da ideia de bandeiristas era oportuna. De resto, o repertório já conhecido consagrou outros bens imóveis: casas de câmara e cadeia, conventos e igrejas. Os tombamentos incidiram sobre bens isolados, monumentais e de valor excepcional. ${ }^{2}$ Nenhum centro histórico foi destacado como de interesse neste primeiro momento, numa estratégia de valoração que assim permaneceu, até 2007, quando se iniciaram os estudos que levaram ao tombamento do Centro Histórico de Iguape, pelo Iphan.

Iguape já havia despertado interesse do Sphan no início dos anos 1940. Em 1942, o fotógrafo Hermann Kruse foi encarregado por Luiz Saia de viajar ao município para realizar " [...] levantamento de plantas e documentação fotográfica de edifícios antigos (igrejas, casas de residências, fortes antigos, etc), pesquisas em sambaquis ou quaisquer outros monumentos naturais ou não que tenham interesse artístico ou histórico [...]" (IPHAN, 2009a, p. 13), conforme escreveu em ofício ao prefeito de Iguape. O relatório de viagem de Kruse afirmava que havia grande interesse na preservação de Iguape, pois a cidade era um "colosso" (Figuras 1 e 2).

Luiz Saia não considerou a preservação de Iguape. Saia alegou ausência de caráter de ancianidade e pouco valor individual das edificações, bem como a sua falta originalidade. Para ele, o tecido urbano e a arquitetura estavam muito alterados pelo período econômico do arroz na região, que ocorreu durante o século XIX, e não justificavam o tombamento.

Alguns anos depois, em 1968, após solicitação de um político local, Lucio Costa sugere a preservação de Iguape pelo Iphan. Mas neste momento, a decisão foi a de apoiar o tombamento em nível estadual. A estratégia adotada pelo Iphan foi a de fomentar a fundação de conselhos e instituições de preservação em nível estadual que pudessem dar conta das pressões sobre o patrimônio, como o crescimento urbano e a especulação imobiliária. Os problemas com a gestão dos bens já tombados, a crônica falta de recursos e de pessoal, aliados à pressão por transformações no ambiente urbano, indicaram a incapacidade de um único órgão nacional que fosse responsável pela proteção nacional (FONSECA, 1997).
Figura 1 - Basílica de Iguape, s/d

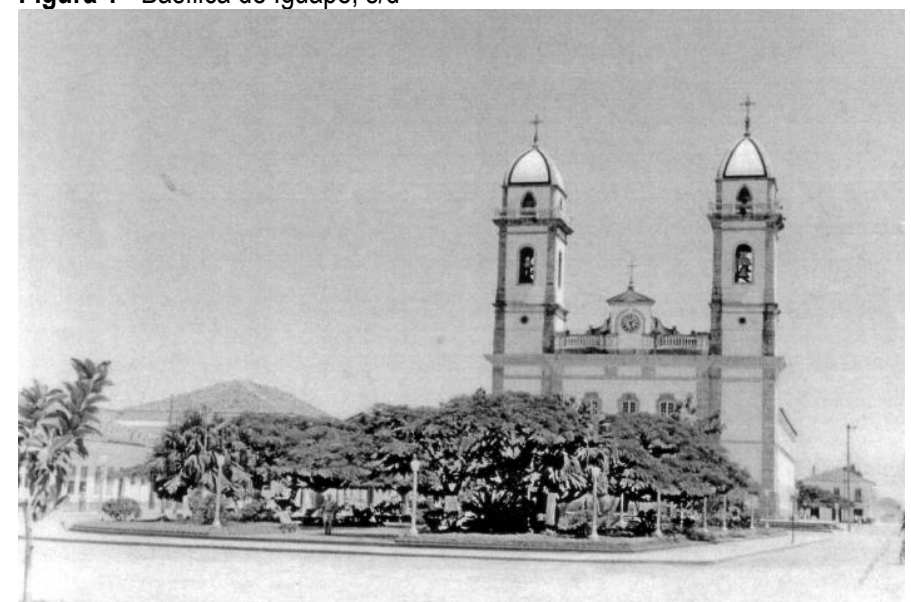

Fonte: Acervo Condephaat

Figura 2 - Rua do Funil, s/d

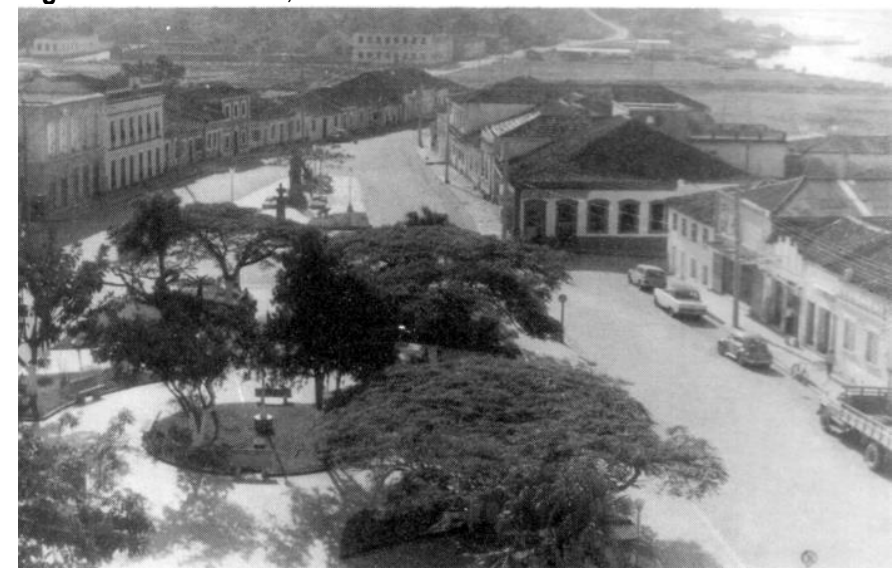

Fonte: Acervo Condephaat

Em São Paulo, a criação do Condephaat foi feita com o apoio da Regional de São Paulo, com o olhar atento e próximo do seu Diretor Luiz Saia. Entretanto, essa escolha por delegar a proteção legal de diversos patrimônios ao órgão estadual, recém-instaurado e que também apresentava os mesmos problemas de infraestrutura, de recursos e dificuldades políticas de enfrentamento das pressões da urbanização, não foi a adotada por todas as Regionais do Iphan no país. Em São Paulo isso acabou resultando em um número relativamente pequeno de bens tombados em instância federal, deixando de expressar o rico e complexo legado cultural paulista. Embora atualmente São Paulo não seja o estado da federação com o menor número de bens tombados, está evidente na listagem de bens tombados pelo Iphan, a ausência de centros urbanos. Além disso, consolidou-se uma visão hierarquizada do patrimônio cultural, na qual os valores nacionais eram supostamente mais importantes que os valores estaduais. Os bens de maior relevância estavam salvaguardados pelo Iphan o que excluiu Iguape desta categoria. 
Em 1975, 67 bens imóveis de Iguape foram tombados pelo Condephaat. Segundo Pinheiro (2013), tratava-se de uma tarefa de fôlego que exigia estudos sistemáticos, pesquisas aprofundadas e um corpo técnico qualificado para tal, o que ainda não existia no Condephaat. Baseando-se na experiência anterior de tombamento de Cananéia, cidade vizinha, adotou-se a metodologia de seleção de bens "em manchas", organizadas a partir de uma somatória de casas antigas. O tombamento de Iguape constituiu-se de quatro manchas complementadas por uma série de construções isoladas. Como bem lembra a autora, apesar do Condephaat ter sido fundado quando já se consolidara a discussão contida na Carta de Veneza de 1964, a concepção de centro histórico presente nesse e em vários outros tombamentos reside em uma somatória de valores individuais isolados e não um conjunto de relações que conforma e define um "sítio urbano como testemunho de um acontecimento histórico ou de uma civilização em particular, incluindo-se neste também as obras modestas e o meio em que se situa", conforme estabelece a carta.

Assim sendo, apesar das mudanças no conceito de patrimônio cultural iniciadas neste momento e de um relativo avanço nas práticas preservacionistas, conforme analisa Rodrigues (2000), as ações do Condephaat em Iguape não chegaram a refletir uma postura mais abrangente e integrada.

Ao longo dos anos, a gestão deste tombamento tornouse conturbada para os moradores de Iguape, que reclamavam de ínfima presença do órgão no município, de pedidos de intervenção que demoravam a ser respondidos, de posturas ambíguas em relação às autorizações de obras e principalmente da ausência de diálogo. Pinheiro (2013), ao analisar os processos internos do Condephaat relativos à aprovação de obras e intervenções no patrimônio de Iguape e Cananéia identifica que, desde o início, o relacionamento entre prefeitura local e órgão estadual não foi fácil. A autora afirma que se construiu uma imagem negativa do Condephaat como o órgão repressor e ao mesmo tempo incapaz de implementar qualquer medida compensatória como o investimento de recursos econômicos nos patrimônios tombados.

É justamente este cenário conflituoso que se constituiu no primeiro grande desafio quando se iniciaram, em 2007, os estudos do Iphan para o tombamento federal na cidade. A opção pelos estudos no Vale do Ribeira justificou-se em função da própria trajetória da preservação federal em São Paulo: até 2006 cerca de $73 \%$ do conjunto tombado estava circunscrito na chamada macrometrópole paulista, enquanto grande parte do interior do estado e o litoral sul não apresentavam bens até aquele ano.

Mas a principal razão da escolha explica-se em face da significância social da região. Trata-se de uma região que ficou conhecida por ter ficado "à margem do império do café", conforme Papy (1957), fora do principal eixo de crescimento econômico do estado paulista, ao longo de todo o século XX, ou seja, aquele ligado ao trinômio café-ferrovia-industrialização. Se isso resultou em uma posição pouco expressiva na dinâmica econômica do estado, por outro lado, permitiu que ficasse ali preservado um patrimônio natural e cultural riquíssimo: o maior continum de vegetação nativa do estado; a maior quantidade de sítios arqueológicos; manifestações culturais ligadas quer às populações tradicionais de caiçaras $\mathrm{e}$ quilombolas, quer aos primeiros núcleos de imigração japonesa do país; presença de aldeias indígenas; além do farto patrimônio edificado, rural e urbano.

A riqueza cultural e natural contrasta, entretanto, com a situação socioeconômica e condições de vida marcadas pelos níveis de pobreza e índices de baixo desenvolvimento humano, em comparação com outras regiões do estado. A ausência de políticas públicas consistentes voltadas à garantia de permanência a terra e de apoio ao pequeno produtor, de educação e saúde e de combate à pobreza intensificaram esse quadro.

A motivação para a realização desta proposta de acautelamento surgiu em 2007, quando a Superintendência Regional do Iphan de São Paulo iniciou o trabalho "Paisagem Cultural: Inventário de Conhecimento de Bens Culturais no Vale do Ribeira", desenvolvido no âmbito das ações de inventário do patrimônio cultural promovidas nacionalmente pelo Depam - Departamento do Patrimônio Material e Fiscalização. No âmbito deste projeto-mãe, concretizaram-se diversos produtos: o Dossiê para a Chancela da Paisagem Cultural do Vale do Ribeira, finalizado em 2009; dois outros dossiês de tombamento (Centro Histórico de Iguape e Bens da Imigração Japonesa, em Registro e Iguape); o Dossiê de Registro como patrimônio imaterial do Tooro Nagashi, celebração que é realizada no dia dois de novembro de cada ano, na cidade Registro, vizinha de Iguape. Em memória aos antepassados, lanternas ou "barquinhos" portando uma vela acesa são lançados às águas do Rio Ribeira de Iguape.

A experiência de trabalho no Vale permitiu concretamente dar visibilidade pública a uma região até então de fora do mapa do patrimônio nacional em São Paulo, assim como desdobrar-se, mais recentemente, em ações públicas e recursos 
direcionados ao vale, tais como as obras de restauro em patrimônios da imigração japonesa em Registro e em edificações do Centro Histórico de Iguape, por meio do PAC-Cidades Históricas. Além disso, destaca-se a implantação da Casa de Patrimônio do Vale, sobre a qual trataremos mais adiante.

\section{A proteção de Iguape: construindo valores $\mathrm{e}$ conceitos para o tombamento nacional}

O amplo trabalho de levantamento do Vale do Ribeira de Iguape realizado na primeira fase da pesquisa, conforme mencionado anteriormente, levou a ações específicas do Iphan para a proteção ao patrimônio cultural nos municípios de Iguape e Registro. O pedido de tombamento de Iguape foi o primeiro que se materializou a partir dos contatos com os agentes públicos e privados locais realizados ao longo de 2007. A Prefeitura Municipal de Iguape, por meio de seu Secretário de Cultura, Carlos Alberto Pereira Junior, percebia no patrimônio cultural uma singularidade para o município e estava se organizando para realizar ações na área, seja por meio de projetos de capacitação de mão de obra, seja por meio de pesquisas e publicações e da elaboração de legislação municipal de patrimônio (PEREIRA JUNIOR, 2005). A gama de desafios para a municipalidade no campo da preservação era muito grande e a chegada do Iphan à região foi entendida como uma possibilidade de diálogo e de ajuda. A prefeita de Iguape, Maria Elizabeth Negrão Silva, formalizou o pedido de tombamento ao diretor do Depam, durante o I Encontro de Trabalho do Patrimônio Cultural no Vale do Ribeira, em junho de 2008, promovido pelo Iphan como parte das atividades do festival Revelando Vale do Ribeira. ${ }^{3}$ (Figura 3)

$\mathrm{O}$ pedido de tombamento ao Iphan informava da importância do patrimônio cultural para a identidade da cidade de Iguape Os fortes vínculos culturais dos moradores com a localidade, seja nos aspectos materiais ou sociais revelava que, se experiência com a proteção legal era penosa, ela não era negada. Ou seja, a aproximação pronta e colaborativa com o Iphan por parte dos moradores e gestores reforçava a importância do patrimônio para aquela comunidade. $\mathrm{O}$ estudo de tombamento iniciou-se a partir da formalização do pedido da municipalidade ao Iphan, que passou a trabalhar estreitamente com os funcionários da prefeitura, considerando a produção já elaborada até o momento, bem como as suas demandas para a proteção legal. A municipalidade esteve envolvida o tempo todo no processo de elaboração do Dossiê de tombamento, ajudando com documentos, informações, logística e inclusive hospedagem para toda a equipe envolvida no projeto.

Figura 3 - I Encontro de Trabalho do Patrimônio Cultural no Vale do Ribeira, realizado na Igreja de São Benedito em Iguape/SP em junho de 2008. Promovido pela equipe técnica do projeto como parte das atividades de conversa com a comunidade local e institucional envolvida com tema no Vale, reunindo prefeitos, diretores de parque, técnicos de patrimônio, pesquisadores, professores e movimentos sociais

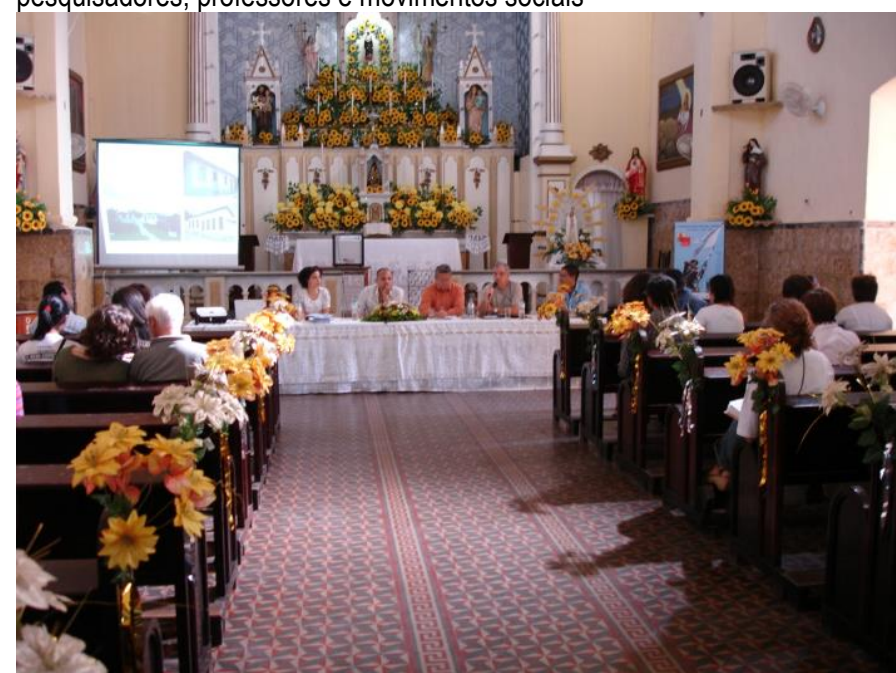

Fonte: Os autores

O primeiro desafio do estudo técnico para o tombamento do Centro Histórico de Iguape foi o de lidar com a proteção legal já realizada pelo Condephaat nos anos 1970. Se, por um lado, o tombamento pelo órgão estadual de patrimônio havia estabelecido uma série de tensões com relação à gestão do sítio, por outro, havia possibilitado a produção de estudos técnicos que permitiam conhecer a área, que foram a base para o início do estudo para o tombamento.

Conceitualmente, partimos das experiências de preservação do Iphan nos anos 1980 de a proteção de sítios urbanos, como as de Laguna/SC e Cuiabá/MT, em que o conceito de cidade-documento permitira novas produções discursivas. Naquele momento, os centros urbanos foram selecionados não apenas por serem monumentos artísticos, mas como documentos dos processos históricos, econômicos e sociais de produção urbana. Segmentos médios que lutavam por qualidade de vida e tomaram o patrimônio como bandeira, somados a minorias e grupos étnicos, levaram à proteção de novos objetos. A redemocratização política, a crise financeira e a falência do modelo de desenvolvimento colocaram o patrimônio na agenda dos anos 1980 como testemunho histórico e dos processos sociais e culturais (SANT'ANNA, 2004, p. 29, 96).

Estas foram experiências seminais de patrimônio nacional que foram nubladas por posicionamentos de patrimônio nos anos 1990, mas que se acreditava ainda 
informar uma prática possível de patrimônio para além da apreciação estética oriunda dos saberes da arquitetura, pensando o campo a partir de demandas sociais. Se o legado prático foi restrito face ao potencial teórico que o conceito de cidade-documento apresentava, o legado conceitual, ao contrário, ainda possibilitava aportes teóricos de grande interesse (NASCIMENTO, 2014).

A partir do conceito de cidade-documento, entendeuse que os processos históricos de formação urbana de Iguape eram o ponto de partida para o estudo de seus bens materiais, quer edificados, quer naturais. As edificações em si, informadas simplesmente por seu valor para a historiografia da arquitetura, não interessavam à proteção proposta. O centro histórico de Iguape foi entendido e estudado no âmbito dos processos históricos formadores da sua materialidade. $O$ que significa dizer que, ao se pensar na materialidade urbana de Iguape atentou-se com muito interesse para as inúmeras sobreposições e rearranjos espaciais constituídos ao longo de muitas décadas, entendendo até mesmo a proteção pelo Condephaat como um dos momentos da história da cidade. As representações históricas de diversos momentos eram a parte evidente de sua feição atual e só teria sentido fazer a proteção legal da cidade, tal como ela havia chegado até o momento presente. Era essa cidade, com seu sítio, seu arruamento e suas edificações e espaços livres que compunham os sentidos identitários, sociais e históricos dos que a habitavam e que assegurariam sua permanência tanto física, quanto simbólica. (Figura 4)

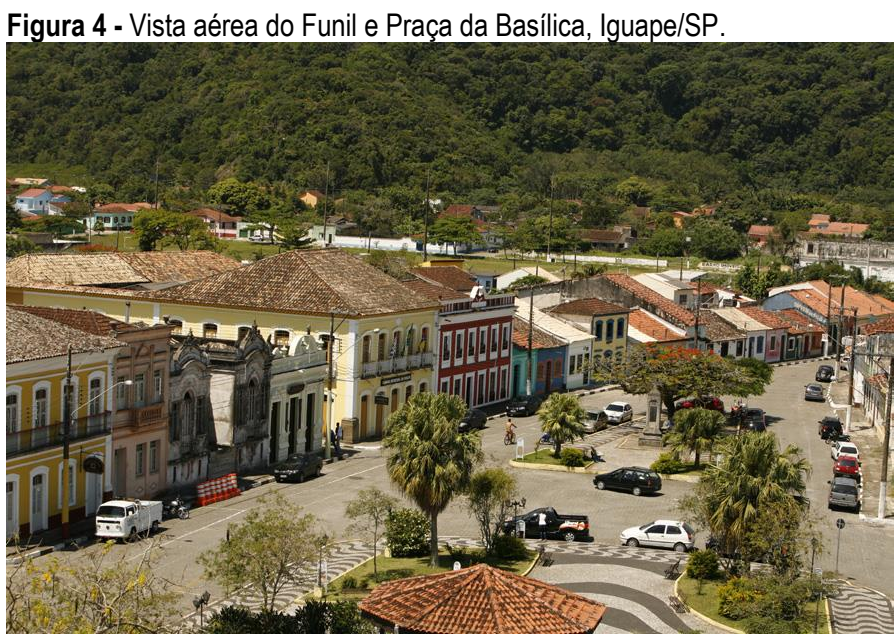

Fonte: Iphan (2009a)

Desde os anos 1980, o Iphan não realizava tombamentos de modo sistemático, sobretudo de centros urbanos. É fundamental dizer que o estudo de Iguape foi viabilizado porque vivia-se uma fase renovada e de grande expansão da atuação do Iphan em todo território nacional. Expandir o que se chamou "estoque patrimonial" foi uma das bandeiras da gestão de Luiz Fernando de Almeida como presidente do Iphan. Isso levava à necessidade de novos parâmetros para a preservação do patrimônio edificado. Aumentar o número de cidades tombadas em nível nacional, de modo a estabelecer uma rede de núcleos urbanos formadores do território nacional, era um dos objetivos da gestão em curso. A atribuição de valor aos novos núcleos tombados deveria se fazer a partir de critérios para além dos consagrados na história do Iphan, como os estético-estilísticos. Dalmo Vieira Filho, diretor do Depam, durante a referida gestão, cunhou o lema de que: "[...] o Iphan não preserva o passado; atua no que precisa fazer parte do futuro". Para tanto, partia do princípio de que, "[...] patrimônio, na contemporaneidade, qualifica espaços urbanos, amplia autoestimas, confere valor, distingue, excepcionaliza e identifica cidades e lugares, tornando-se parte integrante dos atributos e dos potenciais de desenvolvimento dos países e das sociedades" (VIEIRA FILHO, 2010).

A política do Iphan assinalava a potencialidade do patrimônio e das políticas de preservação para o desenvolvimento local, relacionando os sentimentos locais e singulares de autoestima e pertencimento, abrindo-se a possibilidade de proteção em nível federal de inúmeros imóveis e centros urbanos nuançando posicionamentos históricos da instituição. (NASCIMENTO, 2011) O tombamento de Iguape é indissociável deste momento institucional dos anos 2000. A abordagem regional do estudo e a escolha do Vale do Ribeira como área de atuação para o Iphan coadunava com a ideia em curso do patrimônio com maior capilaridade na atuação do órgão, incorporando à listagem de bens tombados uma série de bens culturais que não haviam sido selecionados até o momento pelo Iphan (Figura 5).

\section{Iguape: o sítio e a paisagem como memória}

A proposta do Iphan para o tombamento de Iguape tinha como o pressuposto o entendimento do sítio urbano como parte dos processos históricos e culturais da região do Vale do Ribeira. A abordagem regional na sua primeira fase das pesquisas levou ao estudo mais pormenorizado de Iguape com vistas ao seu tombamento e, uma vez partindo dos conceitos da paisagem cultural, este prosseguiu permeando o olhar ao sítio e a proposta de tombamento. 
Figura 5 - Rua XV de Novembro, Iguape/SP.

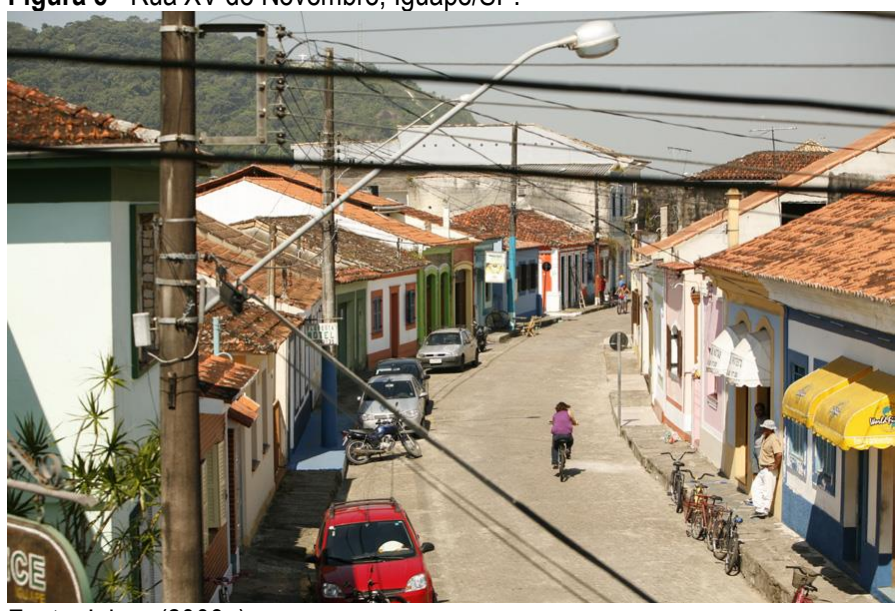

Fonte: Iphan (2009a)

Situada entre importantes marcos referenciais da paisagem, o Morro da Espia, o Canal do Valo Grande e o braço de mar chamado Mar Pequeno, Iguape caracteriza-se por ser plana e composta por importantes casas e sobrados de pedra e cal, com coberturas de telha de barro. Tombar somente as construções significaria apartar da compreensão de sua formação histórica esses elementos e as relações tecidas com a natureza. O estudo buscou, assim, conceber o sítio urbano a partir das relações tecidas com o sítio natural (Figura 6).

Figura 6 - Vista área de lguape/SP.

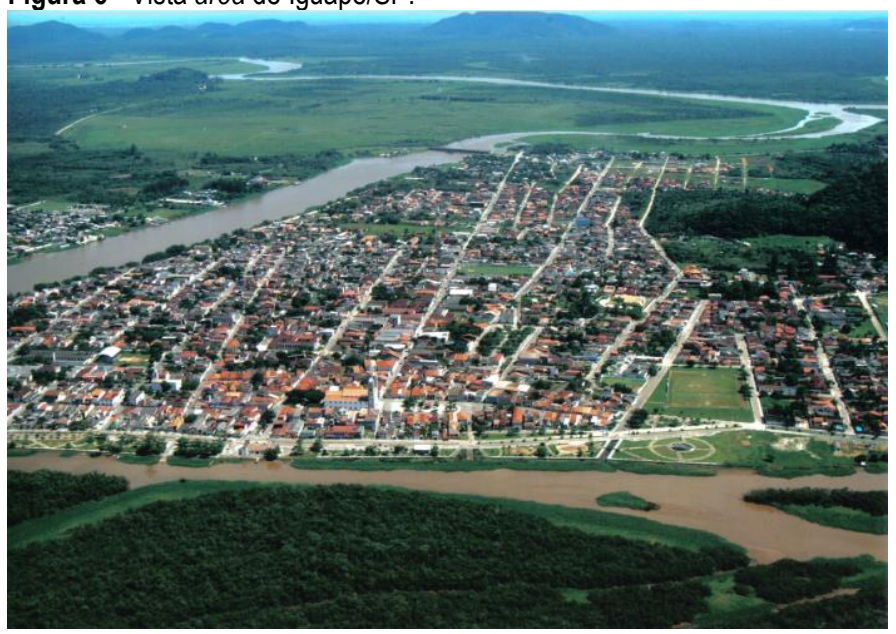

Fonte: Iphan (2009a)

O Morro da Espia, por exemplo, é a razão para que o sítio urbano se localizasse naquele ponto da planície. O primeiro núcleo de povoação, que teve início no século $\mathrm{XVI}$, nasceu um pouco mais ao norte, em um local conhecido como Icapara, situado em planície de mar aberto. A necessidade de proteger o núcleo dos ataques de piratas e corsários e a busca de água potável para a expansão da povoação, levaram a mudança para a base do Morro da Espia. Nesse lugar surgiu a atual Iguape, em 1614, ao mesmo tempo protegida e escondida pelo Mar Pequeno e Ilha Cumprida, com abundantes recursos hídricos em função das nascentes de rios que descem do Morro da Espia, esse desempenhando também função estratégica de vigilância devido a altitude em relação ao conjunto do litoral.

Mas, para além das condições propiciadas para a formação do núcleo urbano em sua localização atual, o Morro da Espia se constitui em um lugar singular e simbólico para a história da cidade. Foi às margens de um riacho, que desce pelas suas encostas, que os moradores lavaram a imagem de Bom Jesus de Iguape, encontrada em uma praia ali perto, por volta de 1647. A imagem, que vinha em uma embarcação de Portugal que foi atacada por piratas, foi jogada ao mar e, devido à corrente marítima, chegou até o litoral sul. Lavada neste riacho, aos pés do morro, a imagem foi colocada no altar da igreja e, nos anos que se seguiram deu origem a festa popular religiosa conhecida como Procissão do Bom Jesus de Iguape, considerada a segunda maior do estado de São Paulo. O riacho cercado de pedras, onde se lavou a imagem é conhecido como a Fonte do Senhor e guarda uma importante lenda da cidade que ganhou notoriedade após a publicação do conto de Albert Camus, "A pedra que cresce". ${ }^{4}$ Segundo o relato de Camus, a cada lasca retirada do local onde foi lavada a imagem, a pedra torna a crescer como em um milagre.

Reconhecendo as íntimas relações entre o morro, a pedra, a fonte e a história de Iguape, a proposta de tombamento tratou de incluir este importante elemento formador, estendendo o perímetro do Centro Histórico de Iguape, incorporando-o como um setor específico da área tombada: o Setor Morro da Espia (Figura 7).

Além do Morro da Espia, outros elementos da natureza de Iguape somaram-se à compreensão de sua formação histórica. Como é o caso da frente de mar interno onde se instalou o Porto Marítimo de Iguape, chamado de Porto Grande, consolidando ali uma função que levou a cidade a momentos de auge econômico e de dinâmica urbana. Atracavam junto ao porto desde pequenas embarcações, canoas e veleiros, até mesmo navios de grande porte como os vapores que cruzavam o litoral paulista, fazendo suas primeiras paradas no Porto de Iguape. No século XIX, várias companhias que faziam navegação de cabotagem pelo litoral brasileiro tinham, em Iguape, um ponto de parada, gerando grande movimentação de embarcações à vapor pelo Mar Pequeno. 
Figura 7 - Vista aérea do Morro da Espia, Iguape/SP.

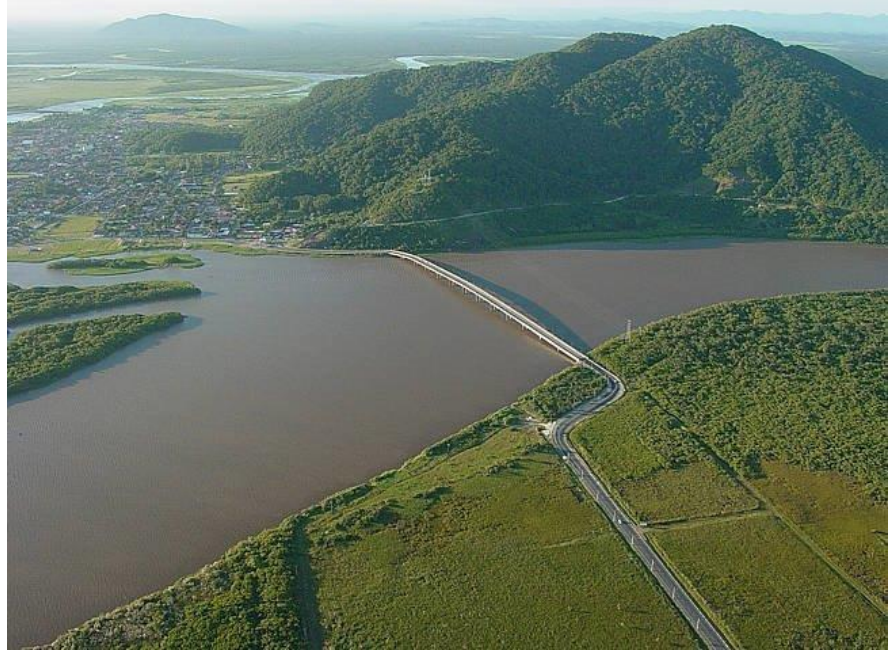

Fonte: Iphan (2009a)

Desta forma, esta frente de mar interno que testemunhou as mudanças ocorridas no sistema portuário, desde sua expansão e consolidação até o seu declínio e fechamento, foi igualmente incorporada ao perímetro de tombamento, constituindo o chamado Setor Portuário. Faz parte também desse setor, um canal de águas artificial, aberto para facilitar o escoamento da produção de arroz e a interligação entre o Porto Fluvial e o Marítimo: o chamado Valo Grande.

Segundo Iphan (2009a), alguns historiadores têm interpretado o Valo Grande como uma obra pioneira na engenharia hidráulica brasileira, talvez pela sua característica específica de intervenção de grande magnitude em um curso fluvial. O Valo Grande, resultado de obras que se iniciaram em 1827, correspondeu originariamente a um pequeno canal de ligação entre um dos trechos do Rio Ribeira, próximo à cidade de Iguape, até o Mar Pequeno. A abertura desse canal encurtaria o caminho das águas do rio, criando uma nova foz, ao lado da cidade. Na mesma razão da redução da distância até o mar, aumentou a declividade do canal, acelerando a velocidade das águas e, portanto, seu potencial de erosão das margens. O solapamento das margens levou ao assoreamento do Mar Pequeno e a formação de grandes ilhas onde antes só havia águas. A redução da profundidade do Mar Pequeno inviabilizou o transporte, inicialmente de navios de grande calado, mas posteriormente só possibilitando o trânsito de canoas. O Valo Grande constituiu, assim, elemento significativo da história que explica a decadência da função portuária e da

cidade de Iguape no contexto da economia paulista. Incorporá-lo ao patrimônio tombado significou reconhecer que a função social da memória para além do que é celebrativo.

\section{O sítio urbano: urbanização e preservação}

Nestes termos, a concepção integrada do Centro Histórico superou a visão do patrimônio como somente o edificado, tal como fez o órgão estadual tombando exemplares pontuais, o que resultou em um desenho de proteção mais complexo, que compreendeu os objetos a partir de sua relação no todo urbano e não tomados individualmente.

O tecido urbano de Iguape está claramente vinculado à sua história e ao momento de ocupação do território brasileiro, em que a defesa era fator central para escolha do sítio. O primeiro núcleo urbano foi implantado junto à barra do Rio Ribeira de Iguape, em Icapara, que logo se mostrou vulnerável, já que junto ao mar aberto. O sítio onde se desenvolveu a cidade é bastante significativo do ponto de vista da defesa e da possibilidade de circulação. Iguape está estrategicamente localizada junto a três marcos na paisagem da baixada do rio de Ribeira: a oeste, o Morro do Espia, elevação de grande destaque toda a região majoritariamente plana, no norte, a cerca de dois quilômetros do que hoje é o centro histórico, o rio Ribeira de Iguape, grande eixo de circulação de produtos como ouro e arroz em toda a história da região e, no sul, o braço de mar, chamado Mar Pequeno. Este garantia fácil acesso ao mar aberto, mas também, lhe dava certa proteção, por ter a Ilha Comprida à sua frente.

A implantação do sítio urbano de Iguape, portanto, tirou partido dos elementos geográficos singulares da região, tendo em vista os objetivos de conquista e desbravamento dos colonizadores. Diferentemente de outras cidades coloniais que lhe são contemporâneas, a cidade não foi construída em alto de elevações, o que lhe tornava mais vulnerável. Esta é uma das explicações para o traçado original do núcleo, fechado ao exterior, voltado para si mesmo e com aspecto de fortificação. Suas ruas em forma de funil, com pequenas aberturas para o exterior, dispostas em semicírculo, como a rua XV de Novembro, contribuíam para o controle do núcleo urbano.

A função de controle conferiu a Iguape tecido bastante singular. O núcleo inicial, implantado em terreno de topografia praticamente plana, tem formato que se assemelha a uma elipse de pontas alongadas, onde estão os chamados funis. As curvas suaves, as pequenas vielas, o traçado não ordenado, com pequenos largos e repleto de esquinas, garantem ao transeunte percursos dinâmicos e ricos em visadas e perspectivas. $\mathrm{O}$ núcleo central da cidade, composto por cerca de trinta quadras, é conformado por lotes de pequena testada, variando entre 2,5 e 8 metros. $\mathrm{O}$ contraste das 
pequenas ruas com lotes estreitos é a grande praça da Basílica do Bom Jesus, cuja imponente construção domina todo composição do conjunto imediato e da cidade.

Procurou-se olhar o sítio urbano de Iguape a partir da lógica dos processos de urbanização da América Portuguesa, recorrendo à farta bibliografia sobre o tema que a historiografia vem produzindo, a qual desmistifica os argumentos de desleixo e espontaneidade (BUENO, 2012). Várias características da urbanização portuguesa são verificáveis na cidade de Iguape, como a localização e escolha do sítio, o arruamento a partir de uma malha conceitual, a estrutura de lotes e quarteirões, bem como o esquema de espaços livres. Identificá-los e tê-los em conta como um valor à preservação legal da cidade foi um importante desafio da produção do Dossiê e da estruturação da proposta de tombamento. A partir da percepção destas características do espaço interurbano, da sua relação com os aspectos naturais do sítio e das indicações da comunidade, sobre a qual falaremos adiante, é que se construiu a proposta do dossiê (Figura 8).

Figura 8 - Perímetro tombado pelo Iphan em Iguape/SP, onde se vê a área urbana, o Morro da Espia e Canal do Valo Grande.

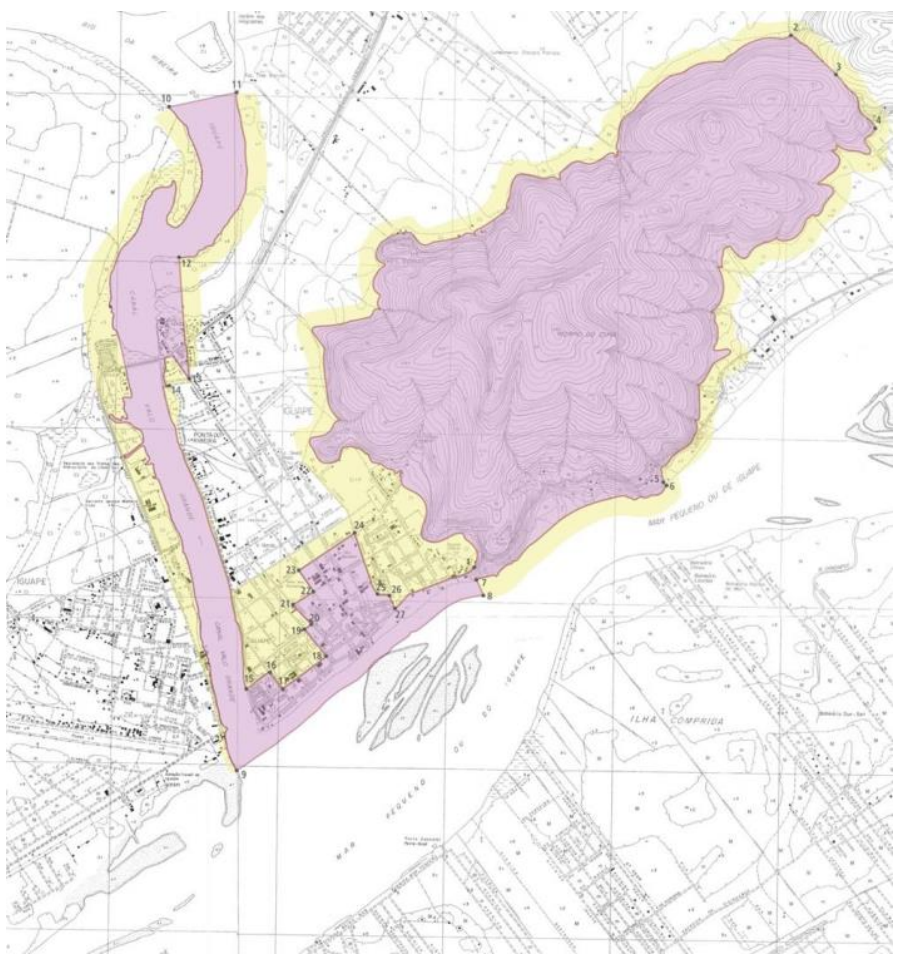

Fonte: Iphan (2009a)

Para que o estudo abarcasse a complexidade do sítio a ser protegido, tratou-se de produzir documentação cartográfica, iconográfica e técnica sobre a área. No espaço interurbano o estudo não se ateve apenas às grandes edificações monumentais. Foram realizadas fichas de inventário para todos os bens incluídos na poligonal de tombamento, perfazendo mais de 750 fichas do Módulo Cadastro (Fichas M301 e M302) do Sistema Integrado de Conhecimento e Gestão (SICG) do Iphan. Como na legislação de tombamento do Iphan não há hierarquia ou graus de proteção diferenciados, era fundamental identificar e conhecer com detalhe o estado de conservação de todos os bens imóveis dentro da poligonal proposta ao tombamento. Em cada ficha constavam informações básicas dos imóveis, com fotos atuais e antigas (sempre que possível), a proteção incidente, o proprietário, estado de conservação e etc. Assim pode-se ter um registro detalhado dos bens imóveis que compõem a área tombada. Tal registro comprovou-se de extrema importância, pois verificou-se que haviam diversos conflitos de informação na documentação do Condephaat, inclusive de mudança de numeração dos bens tombados.

O estudo de tombamento de Iguape foi elaborado num momento de expansão do estoque patrimonial do Iphan em que a necessidade de estudos técnicos detalhados era demandada como exigência para o novo momento institucional. $\mathrm{O}$ estudo técnico se ateve à produção minuciosa de documentação sobre o sítio urbano, resultando num material que pode dar consistência à proposta de proteção do primeiro tombamento urbano do Iphan no Estado de São Paulo. A proposta final de tombamento, aprovada pelo Conselho Consultivo do Iphan, resultou do estudo aprofundado do processo de urbanização do sítio urbano de Iguape, contemplando a complexidade de sua produção social. Ficaram tombados os elementos edificados e naturais que historicamente produziram seu espaço urbano e hoje o conformam como memória e identidade, tal como legitimados pela população local durante os processos de Educação Patrimonial, realizados de modo pioneiro durante a elaboração do dossiê.

\section{0 protagonismo da educação patrimonial}

A experiência de tombamento em Iguape, assim como as ações para a paisagem cultural do Vale do Ribeira, foi também precursora de um olhar renovado sobre a chamada Educação Patrimonial, propondo repensar criticamente o que seria o seu papel e o seu lugar dentro do processo de patrimonialização. Nesse sentido, procurou-se inverter a lógica tradicional dos órgãos de patrimônio, que comumente separam e hierarquizam as atividades da preservação iniciando com a pesquisa, identificação e proteção legal, para depois, em uma etapa sobressalente ou complementar, 
desenvolver atividades educativas, as quais, via de regra, apresentam conteúdos predominantemente de divulgação. Rejeitando sua condição de apêndice e de etapa final, a concepção adotada foi de que a Educação Patrimonial deve ser componente essencial ao processo de identificação e, portanto, deve se dar pari passu e integrada aos estudos de tombamento ou elaboração de quaisquer inventários patrimoniais. Trata-se, dessa forma, de um novo lugar conferido às atividades educativas no conjunto das ações preservacionistas, como já também já destacou Danilo Pereira (2013).

A concepção educativa envolvida no tombamento de Iguape compartilhou da crítica de Silveira e Bezerra (2007), em relação à "ideia redentora de conscientizar o outro" no campo do patrimônio. Para os autores, [...] "as perspectivas conscientizadoras desconsideram a visão de mundo dos envolvidos com o processo de conservação patrimonial, tendendo a tomá-los como pessoas que necessitam da luz do conhecimento para aclarar suas consciências obtusas" (op.cit, p.87). Tal postura "conscientizadora" é aquela que reproduz ações baseadas em uma visão mecânica de educação como transmissão de informações, aquilo que Freire (2011) chamou de concepção bancária, depositária de conteúdos alheios à experiência prática dos educandos e para a qual esses têm apenas o papel passivo, não se colocando como sujeitos do processo. As cartilhas informativas são o principal veículo para esse tipo de educação bancária em patrimônio e tem sido objeto de críticas por aqueles que buscam a renovação de pensamento neste campo de atuação.

Rejeitando esse tipo de Educação Patrimonial meramente informativa, instrumento de promoção ou de divulgação de um patrimônio concebido "de fora", a partir de um olhar essencialmente dos técnicos, as ações de Educação Patrimonial em Iguape basearamse no princípio norteador da construção coletiva da ideia de patrimônio, a partir da valorização do olhar dos moradores locais e de suas memórias.

As atividades desenvolvidas ao longo dos dois anos de atuação em Iguape objetivaram criar canais de aproximação e de interlocução entre o Iphan e os moradores e, sendo assim, centraram-se, muito mais em processos de escuta e de participação, do que propriamente na imposição de um discurso "de fora".

Do conjunto de atividades desenvolvidas destacam-se duas ações principais que buscamos aqui dar destaque: a realização de oficinas de escuta sobre o patrimônio local e a abertura da Casa do Patrimônio, uma experiência pioneira dentro do Iphan.
No primeiro caso, as Oficinas de Educação Patrimonial chamadas de Mapa do Patrimônio, e realizadas em parceria com a Prefeitura Municipal de Iguape, buscaram criar um espaço de interlocução com os moradores da cidade, convidando-os para contribuir na definição sobre o tombamento. Segundo o material de divulgação para a oficina sinalizava-se para a ideia de "construir coletivamente um mapa de Iguape que reúna suas histórias, as memórias de seus moradores e pontue os lugares dos acontecimentos especiais que marcaram a construção da cidade" (PEABIRUTCA/IPHAN, 2008a). Foram duas oficinas realizadas com um público que variou de professores, técnicos de prefeitura e agentes culturais da cidade, a alunos das escolas públicas e jovens do Projeto Oficina Escola de Artes e Ofícios de Iguape (Oficina POEAO).

A metodologia da oficina baseou-se no que atualmente se denomina cartografia social, conforme conceitua Acselrad (2008), ou seja, em estratégias de mapeamento participativo com foco na identificação, por parte dos moradores locais, do que deveria ser objeto de inclusão na proposta de tombamento, ou seja, um processo de escuta como instrumento de decisão.

Para além dos bens que poderiam ser considerados icônicos do centro histórico, todos eles já tombados pelo órgão estadual, outras edificações e lugares foram citados como representativos da memória coletiva: as ruínas de uma antiga fábrica de beneficiamento de arroz, a orla junto ao Mar Pequeno e o porto marítimo, o Morro da Espia e a Fonte do Senhor, o porto fluvial, o cemitério e o Valo Grande, além de outros mais, cuja importância para a compreensão histórica de Iguape já foi abordada anteriormente. Assim sendo, as oficinas colocaram para a equipe técnica o desafio de pensar na elaboração de uma proposta a ser apresentada ao Conselho Consultivo cujo desenho contemplasse as expectativas geradas por meio da participação social. Os processos de escuta somente são participativos quando se tornam instrumentos de decisão compartilhada. As justificativas de inclusão destes bens na poligonal de tombamento basearam-se nos argumentos técnicos levantados pelo estudo e na relevância dos bens para a memória coletiva.

O tombamento de Iguape também se apresentou como inovador na história do Iphan em função da abertura da primeira Casa do Patrimônio no estado de São Paulo e, principalmente por isso ter se dado seis meses antes do tombamento oficial pelo Conselho Consultivo, em dezembro de 2009.

De acordo com a Carta de Nova Olinda (Iphan, 2009b), a proposta de criação das Casas do Patrimônio se 
fundamenta na necessidade de estabelecer uma nova relação entre Iphan, sociedade e poderes públicos locais, baseada em diálogo constante, esclarecimento de rotinas administrativas resultantes do tombamento e de fomento à capacitação e qualificação de agentes que podem atuar no campo do patrimônio. A partir de 2008, algumas superintendências regionais começaram a se organizar neste sentido, criando em suas sedes ou nos escritórios técnicos as respectivas Casas do Patrimônio.

Mas em Iguape foi diferente. A iniciativa surgiu da prefeitura municipal que se responsabilizou pela viabilização de infraestrutura e o Iphan encarregou-se da concepção educativa e das atividades. Neste sentido, em julho de 2009, seis meses antes da decisão pelo tombamento federal, Iphan e Prefeitura de Iguape abriram a Casa do Patrimônio ${ }^{5}$ com um conjunto de ações educativas tais como: uma oficina de maquetes, voltada à capacitação profissional de jovens do ensino público; um espaço expositivo contendo com painéis explicativos sobre a atuação do órgão na região; e, por fim, a abertura de uma biblioteca especializada em patrimônio, trazendo para a região um acervo de livros atualizado e de qualidade, iniciativa pioneira no Vale do Ribeira.

Durante os anos posteriores ao tombamento, as ações educativas prosseguiram com iniciativas como Iphan Conversa (diálogos promovidos sobre temas relacionados à preservação), Oficinas de Formação (Cores para Iguape) e o projeto Sentidos Urbanos, que promoveu roteiros sensoriais voltados à população local, visando fortalecer os vínculos criados desde a chegada dos técnicos à cidade em 2007 (MENDES, 2011).

\section{Conclusão}

De acordo com o parecer do conselheiro relator do tombamento pelo Iphan, Luiz Phellipe Andrés, caberia ao Iphan, a partir do ato de atribuição de valor, uma grande responsabilidade em não frustrar as expectativas dos moradores que foram criadas por meio dessa nova relação de diálogo estabelecida, o que implicaria não somente em continuidade das ações sob a mesma perspectiva, mas também em seu fortalecimento.

Torna-se, portanto, necessário envidar imediatos esforços para fortalecer a pioneira experiência que se verifica da criação da Casa do Patrimônio de Iguape, garantindo aos técnicos locais mais uma estrutura que venha permitir uma verdadeira integração com a comunidade, bem como na condução de trabalhos de proteção do acervo, na medida em que favoreça parcerias entre os órgãos municipais, estadual e o Iphan (ANDRÉS, 2009).

Por todos os argumentos explicitados neste artigo, especialmente pela opção deliberada na busca de aproximação e diálogo local, o tombamento de Iguape tornou-se, no decorrer dos anos, uma experiência reconhecida pela própria instituição como uma nova maneira de pensar e agir em patrimônio. $O$ parecer final do conselheiro relator registra este reconhecimento, ao destacar a "qualidade do conjunto de estudos cuidadosamente preparados", em 4 volumes e mais de 1850 páginas de documentação. A metodologia envolvida da elaboração do dossiê de Iguape deixa como reflexão a necessidade de políticas de patrimônio mais democráticas, abertas à participação social, como condição essencial não para o seu sucesso, mas fundamentalmente para garantir o direito dos sujeitos do patrimônio de não serem apartados de sua memória coletiva.

\section{Notas}

(1) O estudo de tombamento de Iguape foi coordenado pelas autoras do presente artigo Flávia Brito e Simone Scifoni, que à época do estudo, entre 2007 e 2009 eram respectivamente arquiteta e geógrafa da Superintendência do Iphan em São Paulo. Contou com o apoio de pesquisa e levantamento de dados da Peabiru Trabalhos Comunitários e Ambientais, na pessoa da arquiteta Joana Barros.

(2) Para listagem completa dos bens tombados pelo Iphan ver: http://portal.iphan.gov.br/portal/

(3) Realizado sob os auspícios da Secretaria de Estado da Cultura e gerido pela Abaçaí - Organização Social de Cultura.

(4) Conto do livro "O exílio e o reino". Albert Camus esteve em viagem pelo Brasil, em 1949, e acompanhado de Oswald de Andrade visitou Iguape durante as festividades da Procissão De Bom Jesus de Iguape. Além de fazer menção a lenda neste conto, o autor também trata de Iguape no livro Diário de Viagem.

(5) Atualmente denominada de Casa do Patrimônio do Vale do Ribeira. 


\section{Referências}

ACSELRAD, Henri (org.) Cartografias sociais e território. Rio de Janeiro: Ippur/UFRJ, 2008.

ANDRÉS, Luiz Philipe de Castro. Parecer de conselheiro. Processo de Tombamento 1584-T -2009, Núcleo urbano de Iguape. Brasília: mimeo, 2009.

BUENO, Beatriz. Introdução. Dossiê Caminhos da História da Urbanização no Brasil-Colônia. Anais do Museu Paulista, São Paulo, vol. 20, nº.1, pp. 11-40, jan./jun. 2012.

FONSECA, Cecilia L. O patrimônio em processo: trajetória da política federal de preservação no Brasil. Rio de Janeiro: UFRJ/IPHAN, 1997.

FREIRE, Paulo. Pedagogia do oprimido. Rio de Janeiro: Paz e Terra, 2011.

IPHAN. Centro Histórico de Iguape/São Paulo. Dossiê de tombamento. São Paulo: Iphan/SP, 2009a.

IPHAN. Carta de Nova Olinda. Documento final do $1^{\circ}$ Seminário de Avaliação e Planejamento das Casas do Patrimônio. Ceará, 2009b.

MENDES, Carina. O Iphan e a Casa do Patrimônio do Vale do Ribeira/SP: experiências. In: SCIFONI, Simone (org). Caderno de Educação Patrimonial. Memórias urbanas de Iguape-SP. Universidade de São Paulo, 2011. Disponível em: www.repep.fflch.usp.br Acesso em: 15/02/2015.

NASCIMENTO, Flávia Brito do. Blocos de memórias: habitação social, arquitetura moderna e patrimônio cultural. 2011. 392 páginas. Tese (Doutorado Habitat) - Faculdade de Arquitetura e Urbanismo da Universidade de São Paulo. São Paulo.

NASCIMENTO, Flávia Brito do. Em busca de novos documentos: cidade, história e fontes de pesquisa na prática do Iphan dos anos 1980. In: ENCONTRO DA ASSOCIAÇÃO NACIONAL DE PESQUISA E PÓS-GRADUAÇÃO EM ARQUITETURA E URBANISMO. 3., 2014 São Paulo. Anais ... São Paulo: Mackenzie - PUCCampinas - ANPARQ, 2014.

PAPY, Louis. À margem do império do café. A fachada atlântica de São Paulo. Boletim geográfico, Rio de Janeiro, ano $\mathrm{XV}, \mathrm{n}^{\circ} 137$, pp. 139-163, mar./abr.1957.

PEABIRU-TCA/IPHAN. Inventário de Conhecimento do Patrimônio Cultural no Vale do Ribeira de Iguape. Relatório Final. São Paulo, março de 2008a.

PEABIRU-TCA/IPHAN. Relatório da Oficina do Mapa do Patrimônio de Iguape. Iphan/SP, 2008b.

PEREIRA, Danilo Celso. O Conjunto Histórico e Paisagístico de Iguape: um caso paradigmático das políticas de preservação do patrimônio cultural nacional no Estado de São Paulo. In: ENCONTRO INTERNACIONAL ARQUIMEMÓRIA 4, 2013, Salvador. Anais...Salvador: UFBA, 2013.

PEREIRA JUNIOR, Carlos Alberto. Iguape: Conto, canto e encanto com a minha história. São Paulo: Novha America, 2005. 128 p. il. G

PINHEIRO, Maria Lúcia B. Preservação de sítios urbanos tombados: a atuação do CONDEPHAAT em Cananéia e Iguape, no Estado de São Paulo. In: ENCONTRO INTERNACIONAL ARQUIMEMÓRIA 4, 2013, Salvador. Anais...Salvador: UFBA, 2013.

RODRIGUES, Marly. Imagens do passado: a instituição do patrimônio em São Paulo, 1969 -1987. São Paulo: Unesp / Imprensa Oficial do Estado / Condephaat / Fapesp, 2000.

RUBINO, Silvana. As fachadas da história: os antecedentes, a criação e os trabalhos do SPHAN, 1937-1991. 1991. 210 páginas. Dissertação (Mestrado em Antropologia Social - Programa de Pós-graduação em Antropologia Social, Unicamp. Campinas/SP. 
SANT'ANNA, Márcia. A cidade-atração: a norma de preservação dos centros urbanos no Brasil dos anos 90. 2004. 399 páginas. Tese (Doutorado em Arquitetura e Urbanismo). Faculdade de Arquitetura e Urbanismo da Universidade Federal da Bahia. Salvador.

SILVEIRA, Flávio L.A.; BEZERRA, Márcia. Educação Patrimonial: perspectivas e dilemas. In: LIMA FILHO, Manuel et al (orgs.). Antropologia e patrimônio cultural. Diálogos e desafios contemporâneos. Blumenau: Nova Letra, 2007.

VIEIRA FILHO, Dalmo. A rede de proteção. Brasília: mimeo, 2010.

${ }^{1}$ Flávia Brito do Nascimento

Arquiteta e Historiadora. Doutora. Endereço postal: Rua do Lago, 876, Cidade Universitária, São Paulo, SP, Brasil, Cep. 04280-000

\section{${ }^{2}$ Simone Scifoni}

Geógrafa. Doutora. Endereço postal: Avenida Professor Lineu Prestes, Cidade Universitária, São Paulo, SP, Brasil, Cep. 05508-080 